\title{
Community study of the causes of "natural" sudden death
}

\author{
Anthony C Thomas, Paul A Knapman, Dennis M Krikler, Michael J Davies
}

\begin{abstract}
Three hundred and fifty cases of "natural" sudden death within six hours of onset of symptoms in people ranging in age from 18 to 69 years in Wandsworth were studied using a detailed necropsy protocol to determine the cause of death. Sudden death occurred in $28(8 \%)$ Asians and blacks, but because of the small number they were excluded from the study, leaving 322 cases. Ischaemic heart disease accounted for $189(59 \%)$ of the 322 sudden deaths (155 (65\%) men; 34 (41\%) women) and no proportional increase in instantaneous compared with non-instantaneous sudden death was found. Non-ischaemic cardiac disease was the cause of sudden death in 24 cases $(7 \cdot 5 \%)$. Noncardiac disease included pulmonary emboli, aortic aneurysms, and intracerebral haemorrhage and caused $89(27.6 \%)$ deaths. Alcohol was the cause of nine deaths $(2.8 \%)$ and in $11(3.4 \%)$ cases (six men and five women) no cause of death was found.
\end{abstract}

This study shows that although ischaemic heart disease is the single largest cause of sudden natural death there are other major causes.

\section{Introduction}

In epidemiological studies in which data are taken from death certificates alone it is often assumed that most sudden unexpected deaths are due to ischaemic heart disease.' But when the cause of death on death certificates was compared with the diagnosis made at necropsy in hospital patients a quarter to a third of diagnoses were reclassified into a different disease category. ${ }^{23}$ In Sweden a system of mandatory necropsy exists for deaths occurring out of hospital, and it has been established that half of all unexpected deaths in people who were not under medical supervision were due to ischaemic heart disease. Comparing the results of the necropsy to the cause of death on death certification alone probably reduced the proportion of deaths due to ischaemic heart disease by a tenth.

Though in most sudden unexpected deaths in England and Wales the coroner orders a necropsy, because of the tremendous workload the reports may not give many scientific details. If there is no circumstantial evidence to the contrary it is easy to ascribe death to ischaemic heart disease, given the moderate degree of coronary atheroma that is ubiquitous in Western populations.

With the advent of out of hospital resuscitation from ventricular asystole or fibrillation more and more patients survive "near miss" sudden death. We present a necropsy study that provides more than the usual accuracy in the causes of sudden "natural" death in the Wandsworth district of London.

\section{Methods}

Three hundred and fifty consecutive cases of sudden "natural" death over three years were investigated by a necropsy authorised by a coroner. Sudden natural death was defined as that occurring within six hours of the onset of symptoms in patients who were well enough to lead a normal life, were not in chronic heart failure, and had not seen a doctor within the preceding two weeks and where investigation into the circumstances of death by the coroner's office (a police officer) indicated no unnatural cause of death before necropsy. Cases of patients with a previous history of ischaemic heart disease, hypertension, diabetes mellitus, and respiratory disorders were included only if they fulfilled the above criteria. To minimise competing causes of death the study was limited to deaths in people aged 69 years and under. Cases of the sudden infant death syndrome were excluded.

Before necropsy the coroner's officer obtained a history of the last episode and of any previous medical history from the next of kin. A full necropsy protocol was carried out in every case by ACT or MJD. Blood and urine samples were kept for toxicological analyses and blood alcohol concentrations estimated. Body weight and height were recorded, and routine histology of the heart and other organs was performed.

Postmortem coronary angiography was carried out on the fresh intact heart by injecting the coronary ostia with a warmed suspension of gelatine and barium sulphate at physiological pressure. ${ }^{5}$ After fixation in $10 \%$ formol saline the epicardial coronary arteries were dissected en bloc from the heart, decalcified, and examined by histology at $3 \mathrm{~mm}$ intervals. Cross sectional area stenosis was measured with a digitising pad by comparing the area of the lumen to the area within the internal elastic lamina for each arterial segment. The heart and isolated left and right ventricles were weighed according to the method described by Fulton et $a l,{ }^{6}$ and weights recorded. Ventricular hypertrophy was judged to be present when the isolated ventricular mass exceeded two standard deviations from the mean for normal subjects of that body weight who had died from non-cardiac disease. ${ }^{7}$ The cardiac conduction system and its microvasculature were examined histologically in all cases in which there was no clear cause of death. Pneumonia was defined as morphological evidence of consolidation of the lung.

Ischaemic heart disease was considered to be the cause of death when no other cause was evident at necropsy and there was stenosis of at least half of the diameter of the coronary artery $(75 \%$ stenosis by cross sectional area) at any one point in the major epicardial arteries. Left ventricular hypertrophy was given as the cause of death when present alone, but if it existed with pronounced coronary artery disease as defined above the case was assigned to the ischaemic group.

\section{Results}

Of the 350 deaths, $322(92 \%)$ were in whites, $19(5 \cdot 4 \%)$ in Asians, and nine $(2.6 \%)$ in blacks.

Correspondence to:

Professor Davies. 
Because of the small numbers of Asians and blacks in the study group they were not included in the detailed analysis.

Table I gives the age distribution for the study patients, range 19 to 69 years for men and 18 to 69 years for women. Though men predominated, the sex distribution for the different age groups was similar.

TABLE I-Age and sex distribution of patients who died a sudden natural death. Figures are numbers (percentages)

\begin{tabular}{lrrr}
\hline Age (years) & All $(\mathrm{n}=322)$ & Men $(\mathrm{n}=238)$ & Women $(\mathrm{n}=84)$ \\
\hline $19-29$ & $8(2 \cdot 5)$ & $5(2 \cdot 1)$ & $3(3 \cdot 6)$ \\
$30-39$ & $15(4 \cdot 6)$ & $12(5 \cdot 0)$ & $3(3 \cdot 6)$ \\
$40-49$ & $22(6 \cdot 8)$ & $18(7 \cdot 6)$ & $4(4 \cdot 8)$ \\
$50-59$ & $92(28 \cdot 6)$ & $70(29 \cdot 4)$ & $22(26 \cdot 1)$ \\
$60-69$ & $185(57 \cdot 5)$ & $133(55 \cdot 9)$ & $52(61 \cdot 9)$ \\
\hline
\end{tabular}

Table II gives the organ system responsible for death. Ischaemic heart disease was responsible for just over half of deaths and was more common in men than women. Over half the deaths in men aged between 30 and 50 were due to ischaemic heart disease, but no such deaths occurred in women under 50 . All the deaths from ischaemia were because of atherosclerotic coronary artery disease, apart from those in a woman with isolated coronary artery dissection and a woman with an anomalous artery arising in the pulmonary trunk. In $58(86 \%)$ of the 67 men with a history of angina or an old infarction necropsy confirmed that ischaemic heart disease was the cause of death. The remaining nine did not have ischaemic heart disease though they had been treated for angina without confirmation by angiography.

TABLE II-Causes of sudden natural death. Figures are numbers (percentages)

\begin{tabular}{lrrr}
\hline & $\begin{array}{c}\text { All } \\
(\mathrm{n}=322)\end{array}$ & $\begin{array}{c}\text { Men } \\
(\mathrm{n}=238)\end{array}$ & $\begin{array}{c}\text { Women } \\
(\mathbf{n}=84)\end{array}$ \\
\hline Ischaemic heart disease & $189(58 \cdot 7)$ & $155(65 \cdot 1)$ & $34(40 \cdot 5)$ \\
Respiratory disease & $57(17 \cdot 7)$ & $34(14 \cdot 3)$ & $23(27 \cdot 4)$ \\
Non-ischaemic cardiac disease & $24(7 \cdot 5)$ & $14(5 \cdot 9)$ & $10(11 \cdot 9)$ \\
Central nervous system disease & $14(4 \cdot 3)$ & $7(2 \cdot 9)$ & $7(8 \cdot 3)$ \\
Aortic aneurysm & $11(3 \cdot 4)$ & $10(4 \cdot 2)$ & $1(1 \cdot 2)$ \\
Gastrointestinal haemorrhage & $7(2 \cdot 2)$ & $6(3 \cdot 8)$ & $1(2 \cdot 4)$ \\
Cause unknown & $11(3 \cdot 4)$ & $6(2 \cdot 5)$ & $5(5 \cdot 9)$ \\
Alcohol related & $9(2 \cdot 8)$ & $6(1 \cdot 3)$ & $3(2 \cdot 4)$ \\
\hline
\end{tabular}

Of the 155 men who died of ischaemic heart disease, $113(73 \%)$ died at home; of those dying outside the home, $10(6 \cdot 4 \%)$ died at work. Most deaths were unrelated to physical or emotional stimulus: seven people died while taking vigorous exercise, four while walking, and two while driving, and $34(21 \cdot 7 \%)$ deaths occurred at home in bed.

The deaths were subdivided into those that had been witnessed (observed death -233 deaths) and those where people had been found dead (89). Just over half of the observed deaths occurred within 15 minutes of the onset of symptoms, and most occurred within one hour (table III). There was no difference in the ratio of ischaemic to non-ischaemic deaths occurring in these two subgroups.

The 24 non-ischaemic cardiac causes of death

TABLE III-Proportion of deaths due to ischaemic heart disease at different time intervals

\begin{tabular}{lcc}
\hline & Total No of deaths & $\begin{array}{c}\text { No (\%) of deaths due to } \\
\text { ischaemia }\end{array}$ \\
\hline Observed death: & 123 & $78(63)$ \\
$\quad$ 15 minutes & 69 & $46(67)$ \\
16 minutes to 1 hour & 41 & $21(51)$ \\
$1-6$ hours & 89 & $44(49)$ \\
Found dead & & \\
\hline
\end{tabular}

(table II) included eight cases of severe left ventricular hypertrophy presumed to be due to unrecognised hypertension; four floppy mitral valves; three cardiomyopathies, with one case each of the dilated, hypertrophic, and isolated right ventricular form; three previously undiagnosed aortic valve stenoses; and three cases of acute myocarditis.

Respiratory causes ( 57 deaths) included 22 cases of pneumonia and 12 cases with major pulmonary embolism. Eighteen patients had a history of chronic bronchitis but were neither severely disabled nor noted to be cyanosed before their sudden death; nine had right ventricular hypertrophy indicating pulmonary hypertension. Five deaths were in patients who were known to have acute asthma.

Deaths from central nervous system causes (14) included both intracerebral haemorrhage due to a ruptured berry aneurysm and primary intracerebral haemorrhage. There were five sudden deaths in patients with epilepsy.

There were five cases of acute alcoholic poisoning with inhalation of gastric contents and four cases of alcoholic fatty liver with non-lethal concentrations of alcohol in the blood.

In 11 cases $(3 \cdot 4 \%)$ no satisfactory cause of death could be found either from the necropsy or from a review of the medical history. Toxicological analyses were performed on all these cases and on several others, including all deaths in patients with epilepsy and bronchitis. A variety of sedative, tranquilliser, and mild analgesic drugs were identified, but all drug concentrations in the body were within the therapeutic range, and no case of drug overdose was found. No structural abnormality was found in the conduction system.

Apart from the five cases in which a very high blood alcohol concentration was the direct cause of death alcohol was present in the blood in 57 other cases $(17 \cdot 7 \%)$. In 21 blood alcohol concentrations were over $100 \mathrm{mg} / \mathrm{dl}(22 \mathrm{mmol} / \mathrm{l})$ and in seven over $200 \mathrm{mg} / \mathrm{dl}$ $(43 \mathrm{mmol} / \mathrm{l})$.

\section{Discussion}

The term "sudden" has no agreed universal definition. Periods of up to 24 hours, six hours, one hour, and 15 minutes have all been used. ${ }^{8-10}$ Death that occurs within one minute of the onset of symptoms has been regarded as "instantaneous" death." Goldstein proposed that sudden death should be defined as witnessed death within one hour of the onset of symptoms, emphasising the need for a uniform definition but saying that "the definition of sudden death may be expressed in different terms depending upon the nature and scope of the investigation." Though it has been claimed that the proportion of deaths due to ischaemic heart disease is altered by these different definitions, ${ }^{11} 12$ our findings do not support this view up to six hours.

Our findings of the causes of sudden death within six hours of the onset of symptoms are likely to be representative for similar white populations in Britain. Despite $21 \cdot 5 \%$ of the total population of Wandsworth being born outside the United Kingdom, and $18.4 \%$ having the head of the household born in the New Commonwealth or Pakistan (1981 census statistics), only $28(8 \%)$ of 350 sudden deaths were in non-whites. Non-whites may not be as susceptible to sudden death, or as a group they may be appreciably younger, or this study does not reflect the true incidence of sudden death in non-whites. In other studies it has been suggested that blacks are more susceptible to sudden death than whites, ${ }^{1813}$ and it is unlikely that Asians exposed to a Western environment are immune from sudden death due to ischaemic heart disease. Perhaps 
necropsies are so abhorrent to adherents of some religions that ordinary death certificates are issued and the coroner is not informed despite the death being sudden and unexpected.

If all sudden natural deaths in whites were ascribed without necropsy to ischaemic heart disease our results indicate that the cause of death would be wrong in $35 \%$ of men and 59\% of women. In Britain a death certificate is not issued before a necropsy is carried out by order of a coroner, so retrospective checks for accuracy cannot be made. For men whose doctors had diagnosed angina ischaemic heart disease could be predicted to be the cause of death, but this would lead to a $14 \%$ error.

In clinical series of survivors of cardiac arrest occurring out of hospital an incidence of ischaemic heart disease of up to $86 \%$ has been reported..$^{14-10}$ Considering only the cases of observed death within one hour, our figure is lower. The difference may reflect either diagnostic error when coronary angiography has not been performed after resuscitation or that it is more difficult to resuscitate people who have non-ischaemic disease. Necropsies are carried out by order of the coroner in part to minimise bias in certifying ischaemic heart disease and to record the true incidence of such conditions as rupture of dissecting aneurysms of the aorta.

Though ischaemic heart disease is probably the commonest cause of sudden death during strenuous exertion, ${ }^{17}$ only a few sudden deaths from ischaemic heart disease occur while the person is exercising. In common with reports of other studies ${ }^{9}$ most of the patients who died suddenly from ischaemic heart disease in our study were at home doing nothing in particular.

Data on the non-ischaemic causes of sudden cardiac death from the Swedish necropsy study ${ }^{4}$ and from studies of resuscitated survivors of sudden death occurring out of hospital in whom coronary arteriograms were later found to be normal ${ }^{16} 18-20$ show that severe left ventricular hypertrophy due to hypertension or to aortic valve stenosis is associated with sudden death. There is a high incidence of ventricular arrhythmias in patients with severe left ventricular hypertrophy, ${ }^{21-23}$ and patients with mitral valve prolapse are also thought to have a risk of sudden death. ${ }^{24}$ No morphological abnormality of the myocardium or conduction system was found to elucidate the cause of death in the four cases we studied. All forms of cardiomyopathy may cause sudden death in patients known to be affected, ${ }^{25-27}$ but in a large series of sudden death in a community such as Wandsworth they are minor causes.

A history of high alcohol intake was often concealed or minimised by the next of kin even in the five cases of death due to inhalation of gastric contents with blood alcohol concentrations ranging from 180 to $454 \mathrm{mg} / \mathrm{dl}$ $(39-98 \mathrm{mmol} / \mathrm{l})$. These deaths were thought to be natural before the blood alcohol concentration was known, and such cases are likely to be considered unnatural by the coroner. An amendment of the coroner's rules may now make it easier for the coroner's officer to obtain accurate data on alcohol consumption..$^{28}$ As in other series ${ }^{429}$ an alcoholic fatty liver was the sole pathological finding in some of our cases. Ventricular tachycardia in episodes of binge drinking before sudden death has been recorded. ${ }^{30}$ Although steatosis of the liver is now an acceptable cause of death, there is uncertainty about the mechanism. It was difficult to assess the importance of moderately raised blood alcohol in the face of natural disease, as even this might sufficiently alter myocardial or respiratory function to precipitate cardiorespiratory arrest in someone with advanced coronary artery or chronic respiratory disease.
Chronic lung disease may be difficult to accept as a cause of sudden death in people who are not disabled by respiratory disease, but intermittent hypoxia may lead to ventricular arrythmias in patients with bronchitis - most were found dead in bed at night. In another series of 43 cardiac arrests occurring out of hospital but successfully resuscitated, in seven patients lung disease was the only precipitating factor. ${ }^{18}$ Five unexpected sudden deaths from acute asthma over a three year period in a population of 200000 is in the expected range nationally.

It could be argued that "bronchitis" without evidence of pulmonary hypertension is not an acceptable cause of sudden death. Many cases had coronary stenoses falling just short of $75 \%$ by cross sectional area, which may have contributed to death. Therapeutic concentrations of sedatives, tranquillisers, and mild analgesics were also found in many cases, perhaps depressing respiratory drive at night. Theophylline and catecholamines may potentiate ventricular arrhythmias in patients with subclinical myocardial ischaemia.

Sudden deaths also occurred in patients with a history of epilepsy in whom no other satisfactory cause of death was found after extensive necropsy and toxicological examination.

Patients in whom there is no clear cause of death and in whom the heart is morphologically normal pose a problem since a category of sudden adult death analogous to the sudden infant death syndrome does not exist. Of the 350 deaths which the coroner's officer believed to be natural, 345 were indeed natural, the only exceptions being acute alcohol ingestion. There was no evidence that suicide or murder by poisoning was missed by the coroner's officers' initial investigations.

Failure to identify a cause of death is not unique: in the Swedish study of sudden natural death outside hospital no cause of death was found in $17(1.9 \%)$ of 853 necropsies. ${ }^{4}$ In 19 of 98 patients resuscitated from sudden non-ischaemic death ${ }^{1618}$ no structural abnormality of the heart was found subsequently and had they died the pathologist would probably have agreed that the heart was morphologically normal.

One putative explanation for sudden death in which no cause can be found is a defect of the conduction system or its microvasculature. ${ }^{31-33}$ The results of electrophysiological studies ${ }^{1618}$ of the resuscitated survivors of cardiac arrest occurring out of hospital who have no structural cardiac abnormality show that only a small proportion has demonstrable conduction defects, long QT intervals, or pre-excitation, and thus this is unlikely to be an important cause of sudden natural death.

This study was supported by grants from the British Heart Foundation and the Medical Research Council.

I Kannel WB, Cupples LA, D'Agostino RB. Sudden death risk in overt coronary heart disease: the Framingham study. Am Heart $\mathcal{F}$ 1987;113: $799-804$.

2 Kircher T, Nelson J, Burds $\mathrm{H}$. The autopsy as a measure of accuracy of the death certificate. N Engl f Med 1985;313:1263-9.

3 Cameron HM, McGoogan E. A prospective study of 1152 hospital autopsies. 1. Inaccuracies in death certification. I Pathol 1981;133:273-83.

4 Wennerblom B, Holmberg BW. Death outside hospital with special reference to heart disease. Europ Heart f 1984;5:266-74.

5 Thomas AC, Davies MJ. Post-mortem investigation and quantification of coronary artery disease. Histopathology 1985;9:959-76.

6 Fulton RM, Hutchinson EC, Morgan-Jones A. Ventricular weight in cardiac hypertrophy. Br Heart $\mathcal{F}$ 1952; 14:413-20.

7 Hangartner JRW, Marley NJ, Whitehead A, Thomas AC, Davies MJ. The assessment of cardiac hypertrophy at autopsy. Histopathology 1985;9: 1295-306.

8 Luke JL, Helpern M. Sudden unexpected death from natural causes in young adults. A review of 275 consecutive autopsied cases. Arch Pathol 1968;85: $10-7$

9 Myers A, Dewar HA. Circumstances attending 100 sudden deaths from coronary artery disease with coroner's necropsies. Br Heart $\mathcal{f}$ 1975;37: 1133-43. 
10 Rissanen V, Romo M, Siltanen P. Pre-hospital sudden death from ischaemic heart disease - a post mortem study. Br Heart f 1978;40:1025-33.

11 Friedman M, Manwaring JH, Rosenman RH, Donlon G, Ortego P, Grube SM. Instantaneous and sudden deaths. Clinical and pathological differentiation in coronary artery disease. $\mathcal{F A M A}$ 1973;225:1319-28.

12 Goldstein $\mathrm{S}$. The necessity of a uniform definition of sudden coronary death: witnessed death within 1 hour of the onset of acute symptoms. Am Heart 7 1982;103:156-9.

13 Kannel WB, Doyle JT, McNamara PM, Quickenton R, Gordon T. Precursors of sudden coronary death: factors related to the incidence of sudden death. Circulation 1975;51:606-13.

14 Goldstein S, Landis JR, Leighton R, et al. Characteristics of the resuscitated out-of-hospital cardiac arrest victim with coronary heart disease. Circulation 1981;64:977-84.

15 Hallstrom AP, Cobb LA, Ray R. Smoking as a risk factor for recurrence of sudden cardiac arrest. $N$ Engl f Med 1986;314:271-6.

16 Wilber DJ, Garan H, Finkelstein D, et al. Out-of-hospital cardiac arrest: use of electrophysiologic testing in the prediction of long-term outcome. $N$ Engl $\mathcal{J}$ Med 1988;318:19-24.

17 Northcote RJ, Flannigan C, Ballantyne D. Sudden death and vigorous exercise-a study of 60 deaths associated with squash. Br Heart $\mathcal{J}$ 1986;55:198-203.

18 Rosman HS, Goldstein S, Landis JR, et al. Clinical characteristics and survival experience of out-of-hospital cardiac arrest victims without coronary heart disease. Europ Heart $\mathcal{f}$ 1988;9:17-23.

19 McLaren CJ, Gersh BJ, Sugrue DD, et al. Out-of-hospital cardiac arrest in patients without clinically significant coronary artery disease - comparison of clinical, electrophysiological and survival characteristics with those in similar patients who have clinically significant coronary artery disease. Br Heart $\mathcal{O}$ 1987; 58:583-91.

20 Skale BT, Miles WM, Heger JJ, Zipes DP, Prystowsky EN. Survivors of cardiac arrest: prevention of recurrence by drug therapy as predicted by electrophysiologic testing or electrocardiographic monitoring. Am $f$ Cardio 1986;57:113-9.

21 McLenachan JM, Henderson E, Morris KI, Dargie HJ. Ventricular arrhythmias in patients with

Wannel WB, Schatzkin A. Sudden death: lesions from subsets in population studies. 3 Am Coll Cardiol 1985;5:141-9B.

23 Levy D, Anderson KM, Savage DD, Balkus SA, Kannel WB, Castelli WP. Risk of ventricular arrhythmias in left ventricular hypertrophy: the Framington heart study. Am $\mathcal{F}$ Cardiol 1987;60:560-5.

24 Boudoulas H, Kligfield P, Wooley CF. Mitral valve prolapse: sudden death. In: Boudoulas $\mathrm{H}$, Wooley CF, eds. Mitral valve prolapse and the mitral valve prolapse syndrome. Mount Kisco, NY: Futura, 1988:591-605.

25 Maron BJ, Savage DD, Wolfson JK, Epstein SE. Prognostic significance of 24 hour ambulatory monitoring in patients with hypertrophic cardiomyopathy: a prospective study. $A m \mathcal{F}$ Cardiol 1981;48:252-7.

26 McKenna WJ, England D, Doi YL, Deanfield JE, Oakley CM, Goodwin JF. Arrhythmia in hypertrophic cardiomyopathy. I. Influence on prognosis. Br Heart f 1981;46:168-72.

27 Thiene G, Nava A, Corrado D, Rossi L, Pennelli N. Right ventricular cardiomyopathy and sudden death in young people. $N$ Engl f $\mathrm{Med}$ 1988;318:129-33.

28 Maxwell JD, Knapman P. Effect of coroner's rules on death certification for alcoholic liver disease. Br Med $\mathcal{F}$ 1985;291:708.

29 Randall B. Fatty liver and sudden death. Hum Pathol 1980;2:147-53.

30 Panos RJ, Sutton FJ, Young-Hyman P, Peters R. Sudden death associated with alcohol consumption. PACE 1988;11:423-4.

31 Voigt J. Reflections on the value of histological examination of the cardiac conduction system in cases of natural unexpected death. Forensic $S_{c i}$ 1976;8:29-31.

32 James TN. Normal variations and pathologic changes in structure of the cardiac conduction system and their functional significance. $f \mathrm{Am}$ Coll Cardiol 1985;5:71-8B.

33 Bharati S, Lev M. Congenital abnormalities of the conduction system in sudden death in young adults. $f$ Am Coll Cardiol 1986;8:1096-104.

(Accepted 28 September 1988)

\title{
Lesson of the Week
}

\section{Hyperinfection with strongyloides after treatment for adult $\mathbf{T}$ cell leukaemia-lymphoma in an African immigrant}

\author{
A Pagliuca, D M Layton, S Allen, G J Mufti
}

\section{Strongyloides}

hyperinfection is

frequently fatal but

potentially treatable;

patients at risk should

be screened before

beginning

immunosuppressive

treatment
Academic Department of Haematology, King's College School of Medicine and Dentistry, London SE5 8RX

A Pagliuca, MRCP, registrar

D M Layton, MRCP, lecturer $\mathrm{S}$ Allen, $\mathrm{MB}$, registrar

G J Mufti, MRCPATH, senior lecturer

Correspondence to: $\mathrm{Dr}$ Mufti.
Infection with the intestinal nematode Strongyloides stercoralis is prevalent in tropical and subtropical latitudes, particularly west Africa, the Caribbean, and South East Asia. Once acquired, strongyloides infection may be perpetuated by virtue of the unique autoinfection cycle of the organism. In immunocompromised hosts this process may be enhanced, culminating in dissemination. Up to $77 \%$ of these cases prove fatal. ${ }^{1}$ We report a case of strongyloides hyperinfection that developed after treatment of adult $T$ cell leukaemia-lymphoma.

\section{Case report}

A 27 year old Ghanaian man recently arrived in the United Kingdom presented in November 1987 complaining of bone pain, thirst, and polyuria with widespread lymphadenopathy and an enlarged liver and spleen. Investigations disclosed leucocytosis $\left(53.4 \times 10^{9} / 1\right)$ with numerous large pleomorphic $T$ cells showing multilobed nuclei, hypercalcaemia $(5 \cdot 1 \mathrm{mmol} / \mathrm{l})$, and multiple osteolytic lesions. Fluorescence cytometry showed the $\mathrm{T}$ cells to be of helper (CD4) phenotype with expression of interleukin 2 receptor (CD25) and HLA-DR antigens characteristic of adult T cell leukaemia-lymphoma. Seropositivity to human T cell lymphotropic virus type I (HTLV-I) was confirmed by enzyme linked immunoadsorbent assay (ELISA).

Combination chemotherapy, including high dose corticosteroids, led to rapid reduction in white cells and resolution of the hypercalcaemia. One week after beginning treatment, however, he developed fever, meningism, abdominal pain, and distension with radiological evidence of paralytic ileus. Bacteriological examination showed Streptococcus faecium meningitis and Escherichia coli bacteraemia. Chest $x$ ray examination showed extensive reticulonodular shadowing (figure). Strongyloides larvae were seen in faeces, sputum, and duodenal aspirate. He was treated with thiabendazole $25 \mathrm{mg} / \mathrm{kg}$ daily and antibiotics, nutrition was maintained parenterally, and chemotherapy was stopped. Severe hypoxia (arterial oxygen tension $2 \cdot 6$ $\mathrm{kPa}$ ) due to intra-alveolar haemorrhage developed before recovery ensued. Clearance of strongyloides larvae was confirmed after 10 days. Results of repeated stool examination were negative.

In January 1988 the patient suffered meningeal recurrence of adult $T$ cell leukaemia-lymphoma, which

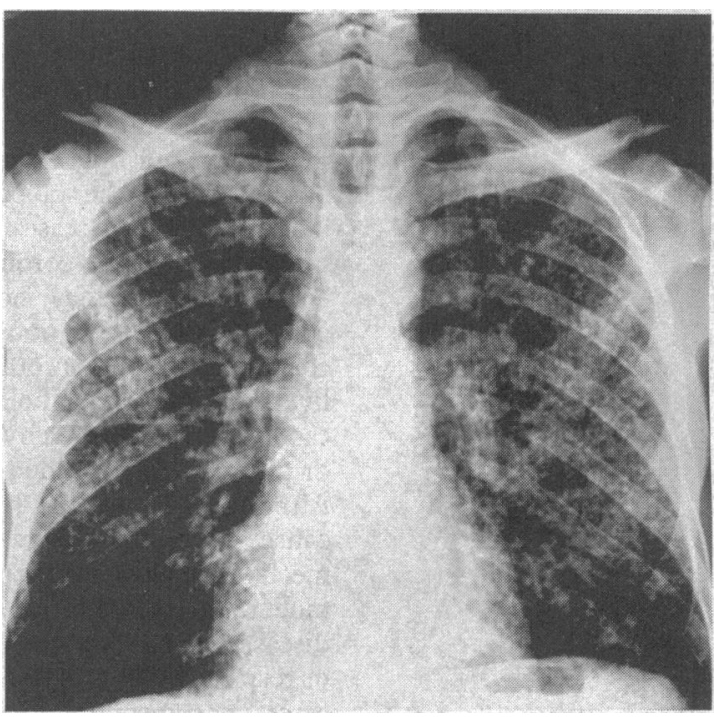

Diffuse reticulonodular shadowing associated with strongyloides hyperinfection 